\title{
HISTORICAL SURGICAL INSTRUMENTS IN THE MUSEUM OF THE ROYAL COLLEGE OF SURGEONS OF ENGLAND (3)
}

\author{
IV. E. Thompson, Ionidon, Exglani) \\ Clevk of the .Huseum, Royal College of Surgeons of England
}

Preserved in a wooden case covered with sharkskin is an example of a spring cataract knife devised by ('iuérin of Lyons in 1785, which represents his second model (Fig. 21). The knife is attached by its stem to a spring in the brass case, and can be set for action by depressing the thumb-lever and pushing it to the right. The ring is then applied to the eye, the thumb presses the lever holding the stem, and the knife moves swiftly across the lower part of the ring, making a corneal flap. By turning the thumb-screw at the base of the case to the right or left, the knife is drawn nearer to, or away from, the ring. Gutirin claimed that it enabled the operator to use it on the right as well as on the left eye. P. Lassus illustrated and described this instrument in his Médecine opératoire (1795). It was presented by Sir Anthony (arlisle in $18: 3.3$.

"The favourite cataract knife of Friederic von Jaeger (1784-1871) of Vienna, the exact model of that made by his father-in-law the celebrated Beer" (1763-1821). This note by the donor, Sir William White Cooper, accompanied the Beer's cataract knife seen in Figure 2.2. Other instruments formerly belonging to von Jaegar are a double hook, strabismus hook, and Charrière's double clip for steadying the eve (Fig. 22.2).

A box containing four cataract knives (Fig. 23) was presented by Mr Jabez Hogg (1817-18999), in 1873, as "a case of cataract instruments presented by Professor Beer to Mr (i. J. Ciuthrie" (1785-1856), president of the College in 18333. Three of the knives are Beer's and the fourth Desmarres's secondary cataract knife, and all are marked with the letter " (, ," (iuthrie's initial. The secondary cataract knife is stamped "Savigny \& "o." and one of the Beer knives shows the letters "gny," the rest of the name being effaced. The late Mr C. J. S. Thompson, Honorary Curator of the Historical Section, believed that Savigny had a branch at Vienna, or that Beer had knives made in London. (i. J. Cruthrie's guarded cataract knife, used by the inventor (Fig. 2:3), is illustrated in the second edition of his Lectures on the Operative Surgery of the Eve (18:7), but it is not identical in pattern. The cutting blade is made of steel and the guard of silver. Another knife was " a favourite knife

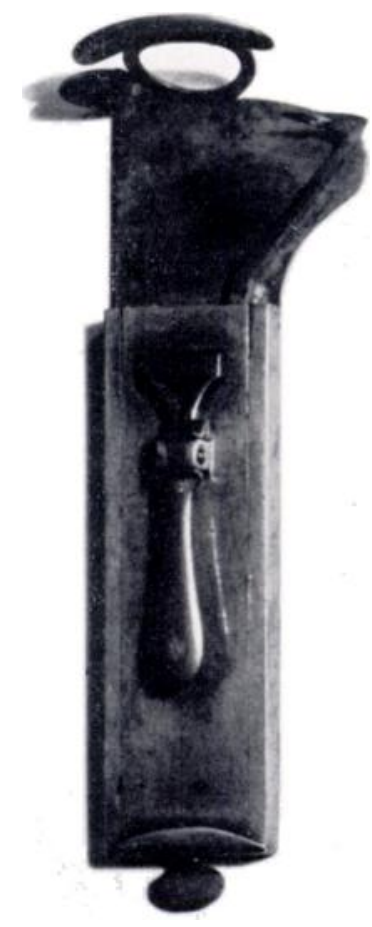

FIG. 21

Cataract knife devised by (iuerin of l. rons in 1785.

of Frederick Tyrrell's." F. Tyrrell (1793-1843) in his A Practical Work on the Diseases of the Eye (1840) described this knife as " a modification of that formerly used by Professor Beer, at Vienna." Tyrrell was an articled pupil to Sir Astley Cooper and his nephew by marriage. A delicately made and complicated instrument is (irossheim-(ieiger's raphiankistron for 


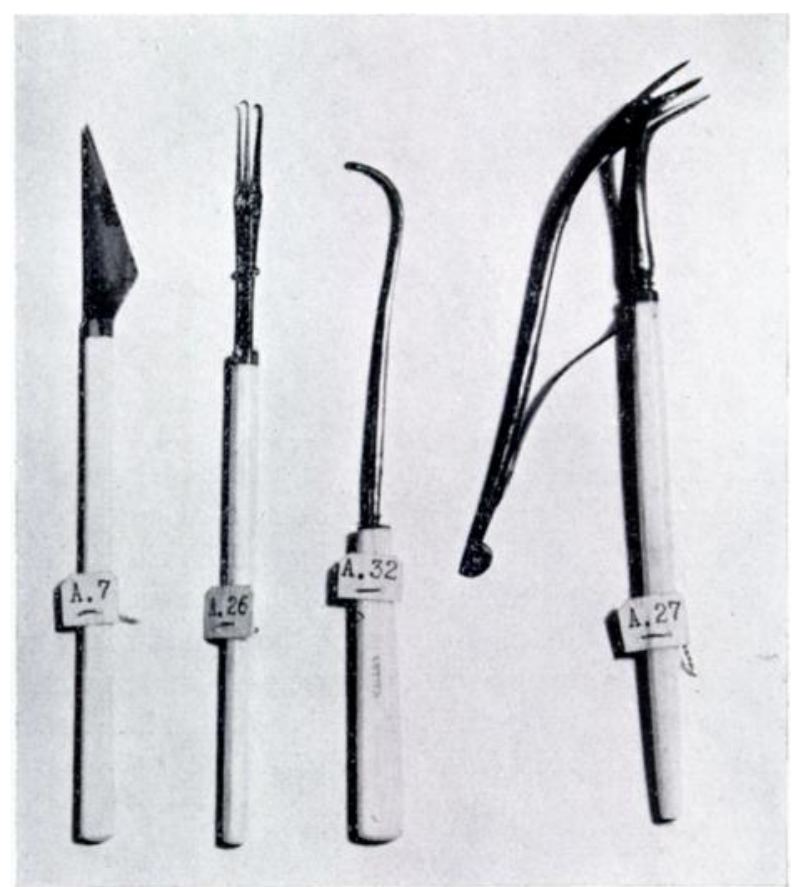

FIG. 22

Four instruments used by Friederic von Jaeger, of ViennaBeer's cataract knife, double hook, strabismus hook, and Charrière's double clip.

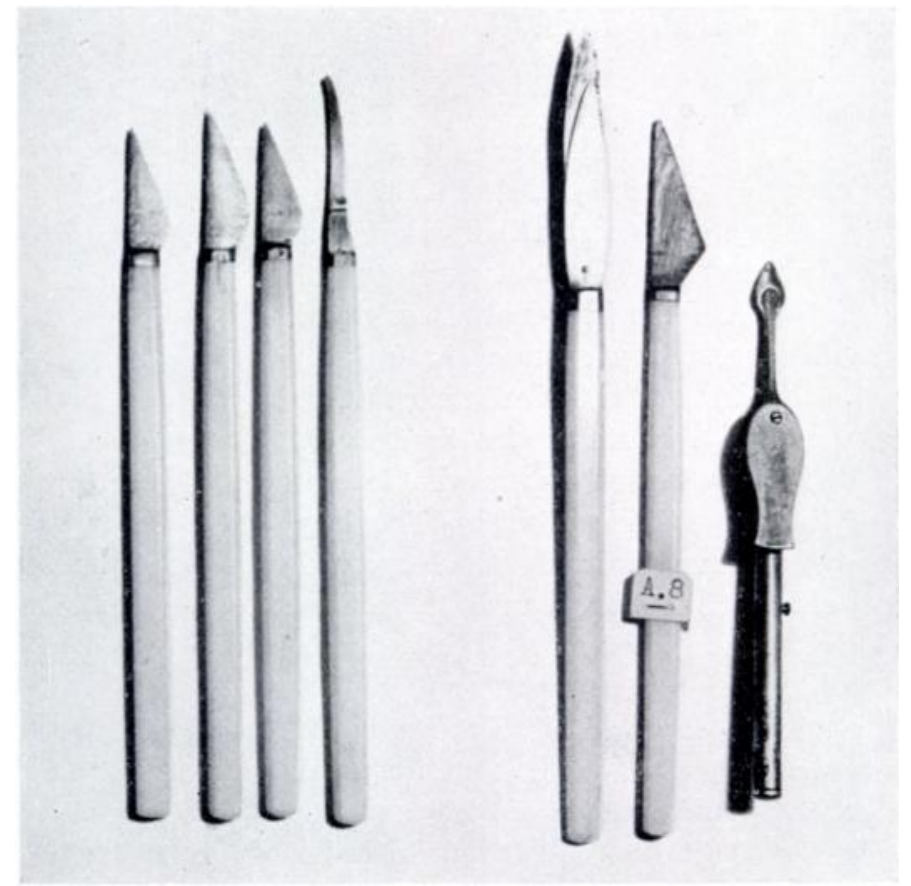

FIG. 23

Left-Three Beer's cataract knives and Desmarre's secondary cataract knife. Third from right-G. T. Guthrie's guarded cataract knife. Second from right-F. Tyrrell's modification of Beer's cataract knife. Right-Grossheim-Geiger's raphiankistron for coredialysis. 
coredialysis. The lance-shaped knife is mounted on a spring, worked by a button moving along a slot in the brass tube. When the button is pushed forward, the knife is protruded until the lance-head lies between the two guards which press into the depression on each of its sides, and so the cornea is incised. On pressing the spring-levers, the knife flies back. Then the guards can be used to grasp the iris, and to detach from its ciliary border as much of it as is desired by the operator. This instrument was described at great length by $\mathrm{E}$. (irossheim in 18:6. When the author was travelling with Prince William of Prussia (afterwards
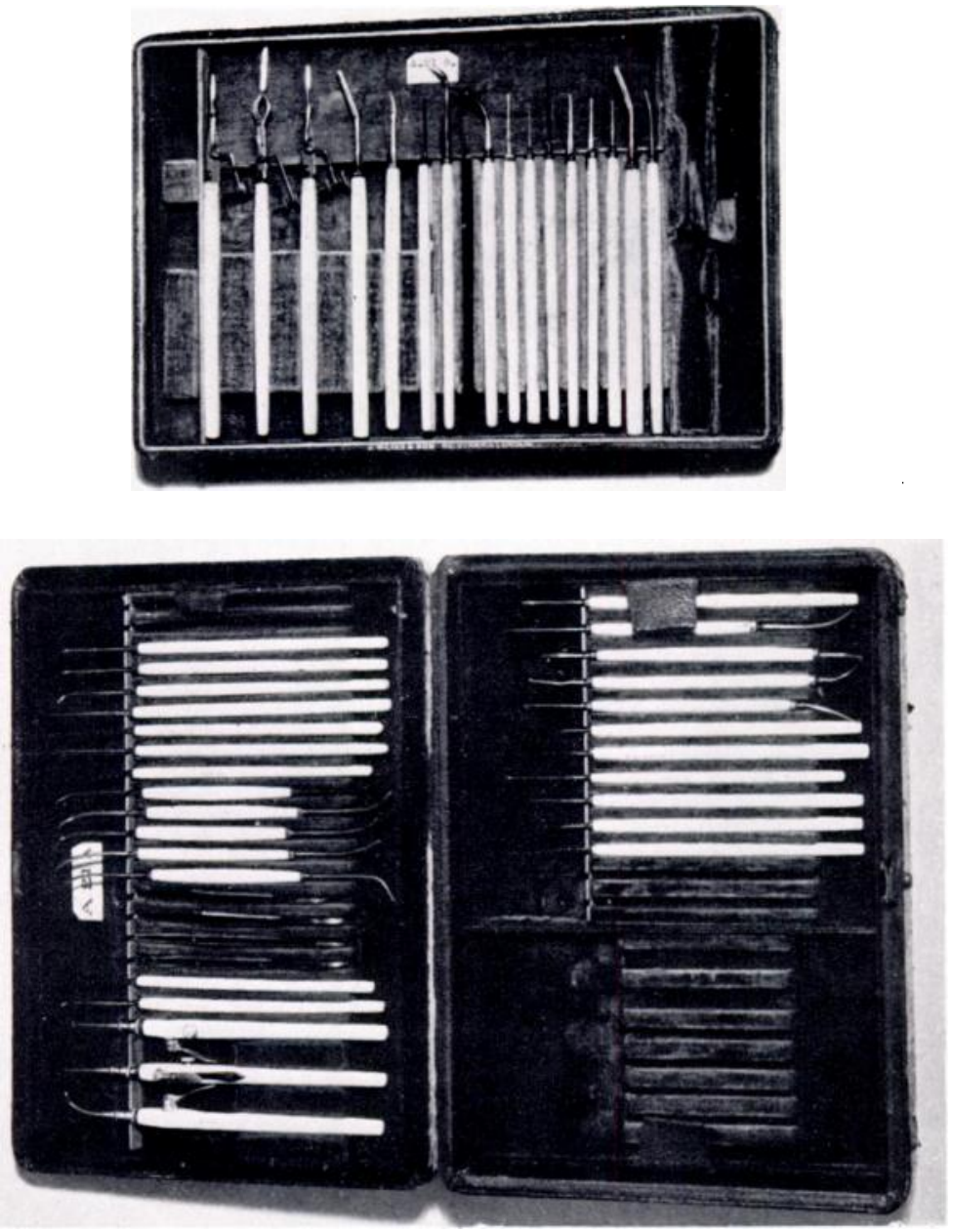

Fig. 24

Two cases of ophthalmic instruments formerly belonging to Sir William Bowman. many of which are of his own invention.

the (ierman Emperor, William I) he designed with the aid " of a most ingenious (ierman instrument-maker, (ieiger by name," this instrument, and Lerche, with other Prussian ophthalmic surgeons, after employing it, all agreed with (irossheim that it was admirably adapted for the making of an artificial pupil. In conclusion, (irossheim dwelt upon its special advantages for iridodialysis (coredialysis). The example shown in Figure $\mathbf{2 3}$ was the property of William Long, F.R.S., and was given to the Museum by his widow in 1818; hence it was made many years before Grossheim published his memoir. This instrument would seem to have been made originally by (reiger, who was probably the sole designer of the raphiankistron, Grossheim effecting some modification in later years.

Vol. $35 \mathrm{~B}$, No. 4 , NoviMBER 1953 


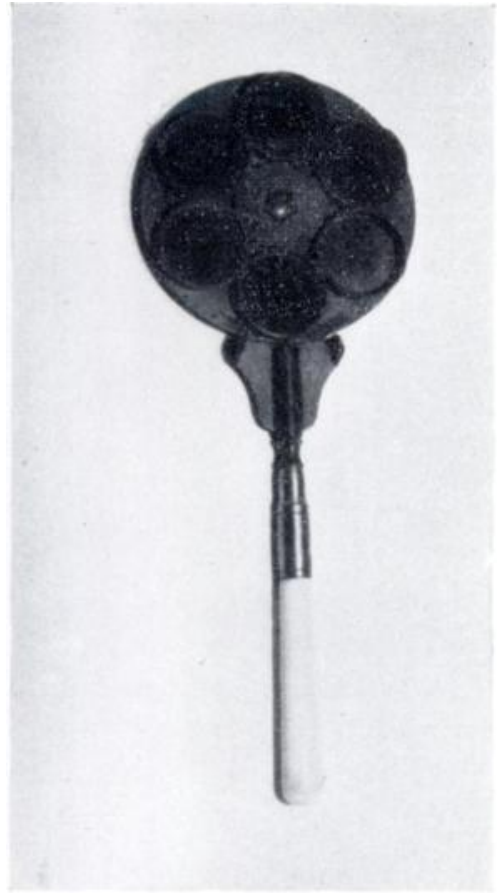

Iig. 25

Dr H. A. Lediard's railway colour testing instrument.
W. E. THOMPSON

There are two cases of ophthalmic instruments which belonged to, and were used by, Sir William Bowman, Bart., F.R.C.S. (1816-1892) (Fig. 24). The larger one was presented by his grandson, the Rev. Sir Paget M. Bowman, Bart., in 19:30; it contains thirty-three instruments, two probes, a small curved needle and some black silk. The other was presented by Mr Thomas H. Court in 19:31, and contains sixteen instruments. In both sets there are instruments of Sir William Bowman's own design.

Lediard's railway colour testing instrument is shown in Figure 2:). It is " a simple instrument designed for the use of surgeons who are required to test the colour vision of men and lads taken for employment on the railway. The colours given are blue, yellow (i.e., the railway signal white light), green, matuve, and red. The test is used by holding the instrument against the light, and turning the disk round, so that the person examined sees the colours in much the same way as he would were he looking at signals." (Lediard 1889). Ir Lediard was the inventor of this instrument, and presented this example, modified from that described in the Lancet, to the Museum in 1919.

In a leather-covered case is preserved the original otoscope invented by Dr John Brunton (18:36-1899)

(Fig. 26). It is the instrument that Dr Brunton exhibited before the Medical Society of London in 1862, and is recorded in the minutes of the Clinical Meeting held on December 8, 1862 as follows: " Dr Brunton practically showed a new auriscope of his own invention and described the nature of its construction." A description of the instrument was reported in the Lancet by Brunton in $\mathbf{1 8 6 5}$. It was presented by I)r John Brunton, the son of the inventor, in 1931 .

The ivory ear trumpet (Fig. : 27 ) was specially made for and used by Admiral Sir John Borlase Warren, Bart. (1753-18:2). It is an elegant instrument consisting of a trumpet, an

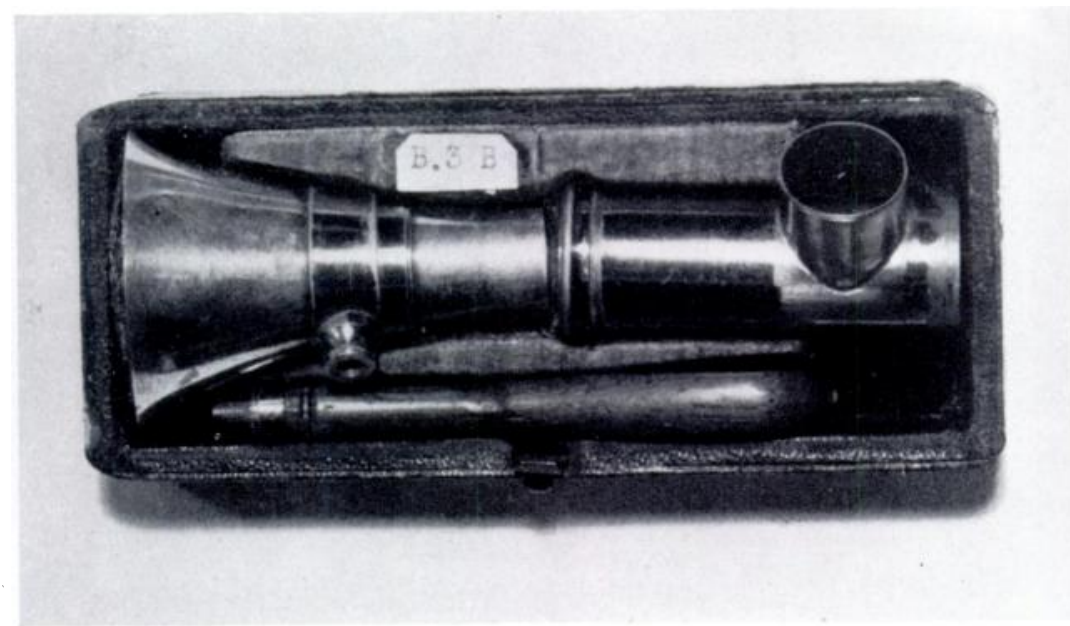

FIG. 26

The original otoscope invented by Dr John Brunton in 1862 . 
earpiece, and a series of cylinders forming a tube. The Itictionary of National Biography (1899) contains an account of Sir John Borlase Warren's life. The instrument was presented by the great-grandson of the Admiral in 1914 .

A heary brass ear syringe made towards the end of the eighteenth century, and before the finger-rings were added to the upper cap of the cylinder and on each side of the piston, is illustrated in Figure 28 . There are also two examples of india-rubber ear syringes of the

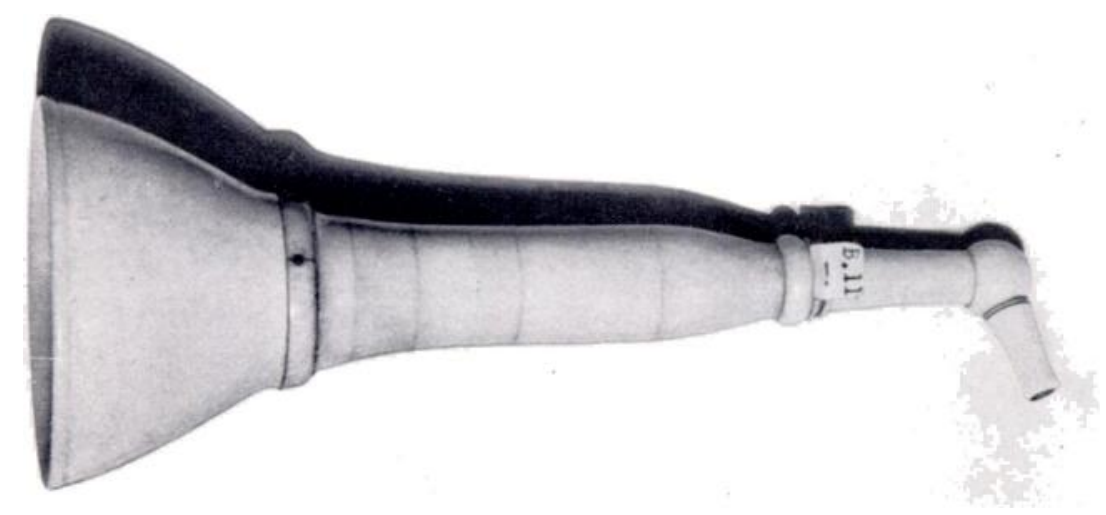

Fig. 27

lvory ear trumpet made for and used by Admiral Sir John Borlase Warren (1753-1822).
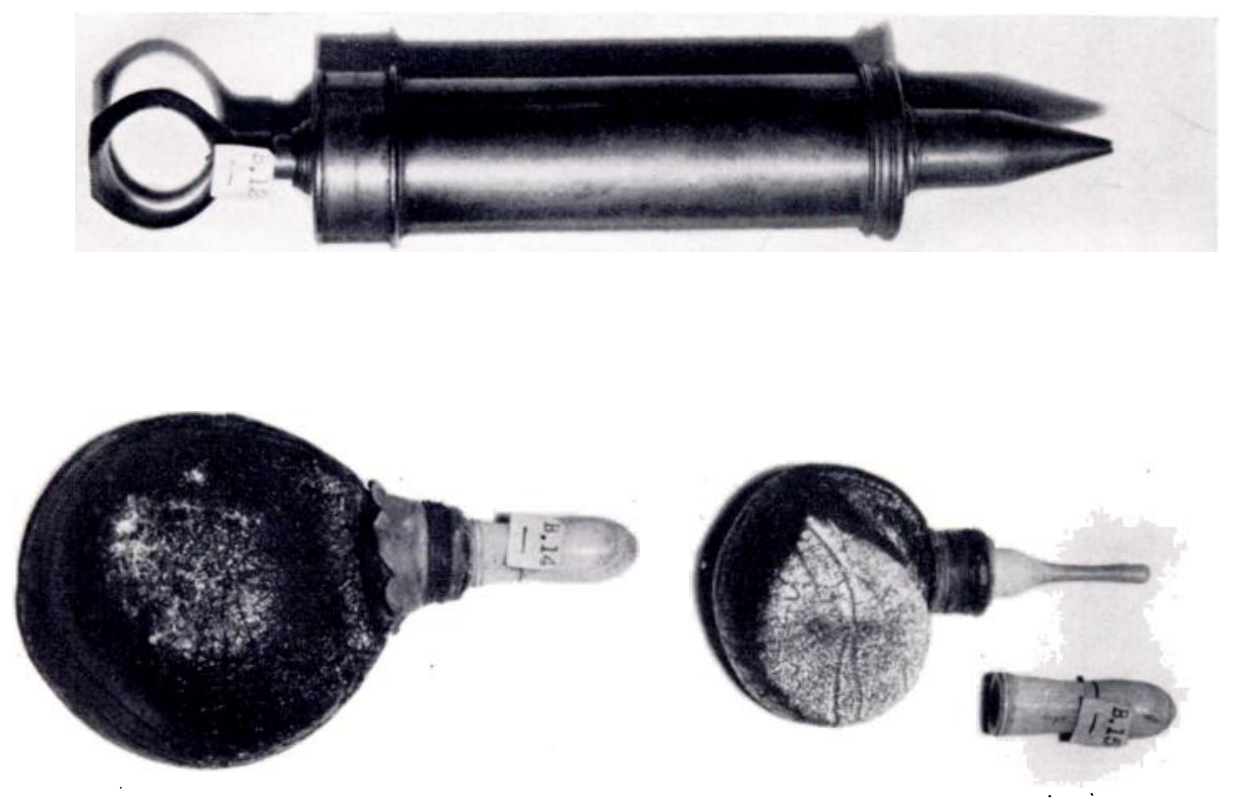

Fili. 28

thoo - Brass ear syringe, late eighteenth century. Belou Two india rubber ear suringes, circa 1800.

earliest type (Fig. 28) which were in use in England about 1800. Savigny in his Instruments (1798) devoted Plate XVIII to "Elastic Bottles," and adds the following: "It is not my intention, nor does it fall within my ability, to enter into the natural history of this wonderful production. I shall only say that, in respect to its mechanical properties, surgery has received few more important acquisitions."

VOL. $35 \mathrm{~B}$, NO. 4, NOVEMBER 1953 


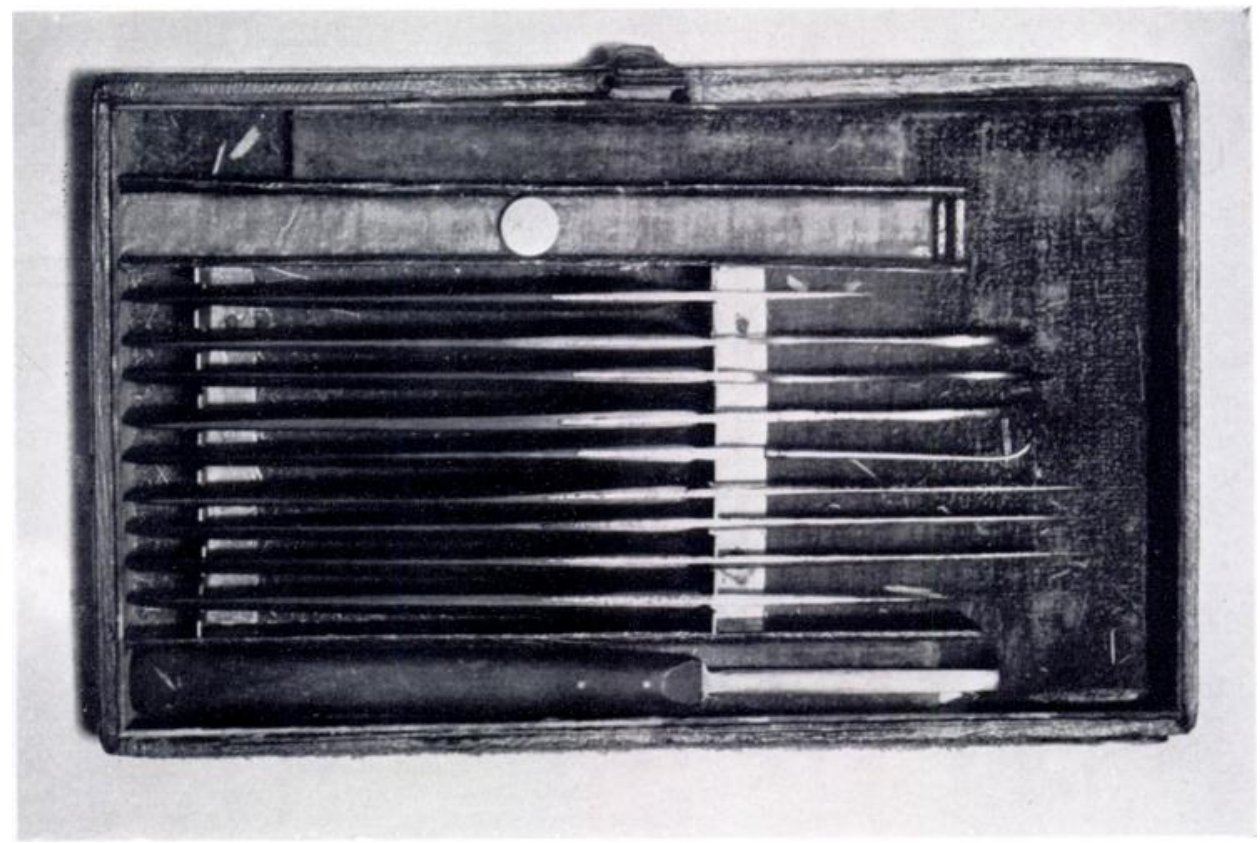

FIG. 24

Case of cleft palate instruments once the property of the inventor, Francis Mason.

A case of cleft palate instruments (Fig. 29) was once the property of the inventor, Francis Mason, F.R.C.S. (1837-1886). The case contains four Mason's cleft palate knives, two Ferguson's cleft palate knives, a small scalpel, three cleft palate suture needles and hempen twine sutures. These instruments were used by their designer in his private practice, and were purchased by the donor, Sir George Makins, Bart., after his death. A silver plate on the lid of the case is engraved "Fcis. Mason" in italics. Reference to the instruments was made in a paper " On Cleft Palate," by Francis Mason, in 1876.

\section{REFERENCES}

Brunton, J. (1865): A New Otoscope or Speculum Auris. Lancet, ii, 617.

Dictionary of National Biography (1899): 59, 412.

1)orax, A. G. H.: Descriptive Catalogue of the Surgical Instruments in the Museum of the Royal College of Surgeons of England. (Typescript in Library, Royal College of Surgeons of England.)

(irossheis, E. (1826): Beschreibung eines neuen Instrumentes zur Iridodialyse. Journal der (Chirurgie und Augenheilkunde, 9, 337.

Guthrik, (i. J. (1827): Lectures on the Operative Surgery of the Eye, 553, 1P. 6. I.ondon: Burgess \& Hill. LAssc's, I'. (1795): De la médecine opératoire. 2, 303 . . Paris: Buisson.

Lediari), H. A. (1889): Colour Test for Railway Purposes. Lancet, ii, 1,156.

Mason, F. (1876): On Cleft Palate. St Thomas's Hospital Reports, N.S. 7, 49

SAvigny, J. H. (1798): Instruments Ised in the Practice of Surgery. I.ondon.

Tyrreli., F. (1840): A Practical Work on the Diseases of the Eye, 2, 391. I.ondon: John (hurchill. 